\title{
Acute Cyanosis Developing after the Placement of Central Venous Catheter: Methemoglobinemia Related to Local Prilocaine
}

\author{
Barbaros Şahin Karagün, Esra Pekpak, Yurdanur Kılınç, Erol Akgül \\ Department of Pediatric Hematology and Oncology, Çukurova University School of Medicine, Adana, Turkey
}

\begin{abstract}
Introduction: Methemoglobinemia is a rare serious hematological disorder, which is one of the causes of cyanosis in childhood, requiring emergency treatment. It may occur in congenital and acquired circumstances. Congenital methemoglobinemia can be a result of a genetic defect in erythrocyte metabolism and hemoglobin structure.

Case Report: Acquired methemoglobinemia occurs in individuals exposed to various oxidant drugs and toxins, but exposure to medication is the most common cause of methemoglobinemia. Local anesthetics such as prilocaine, bupivicaine, and lidocaine are widely used in clinical practice and are common oxidant drugs that cause methemoglobinemia. The diagnosis of methemoglobinemia should be considered in patients presenting with hypoxia and cyanosis. Severity of symptoms correlates with the existing methemoglobin level.
\end{abstract}

Conclusion: In this report, we presented an infant case in which methemoglobinemia developed after the administration of prilocaine prior to the placement of a central venous catheter.

Keywords: Methemoglobin, local nesthetics, cyanosis, ascorbic acid

Received: 14.08.2015 Accepted: 08.10.2015

\section{Introduction}

Hemoglobin is a molecule found in red blood cells that ensures oxygen transport to tissues. Iron found in the heme structure must be in the ferrous state in order to bind to oxygen. Normal level of methemoglobin in total hemoglobin is less than 1\% (1). Methemoglobinemia is characterized by a methemoglobin concentration exceeding $1 \%$ of the total hemoglobin. It is formed through the conversion of iron from the ferrous (Fe+2) to the ferric $(\mathrm{Fe}+3)$ state. Unlike oxyhemoglobin, methemoglobin is unable to bind to oxygen and transport oxygen to tissues leading to cyanosis (1-5).

Methemoglobinemia may occur in the pediatric population because of hereditary or acquired causes. Exposure to drugs and toxins are the major cause in acquired methemoglobinemia. Hereditary causes include deficiencies in nicotine adenine dinucleotide (NADH) diaphorase, cytochrome-b5 reductase, glucose-6-phosphatase, and presence of abnormal hemoglobin. Oxidative predisposition of hemoglobin is greater in the younger age group because of weaker cytochrome b5 reductase activity and higher sensitivity of hemoglobin $\mathrm{F}$ to oxidation than hemoglobin A (1-3).

Placement of permanent or temporary central venous catheters in the pediatric patients with different acuity of disease has become a more common practice since the 1990s. The constriction of venous diameter and vascular development in children has necessitated the use of permanent catheters in the treatment of chronic diseases including leukemia that requires long-term therapies. Administration of medication and collection of blood sample are easier using permanent catheters, and treatment compliance rate is also increased. Anesthetics used during the placement of catheters including benzocaine, prilocaine, and lidocaine are mostly safe and commonly used in the pediatric age group. However, occasionally, they can cause methemoglo-

\section{Address for Correspondence:}

Barbaros Şahin Karagün, Department of Pediatric Hematology and Oncology, Çukurova University School of Medicine, Adana, Turkey

E-mail:drbkaragun@yahoo.com.tr

oCopyright 2016 by Emergency Physicians Association of Turkey - Available online at www.jemcr.org 
binemia manifested as acute central cyanosis; this condition can be confused with complications related to the procedure (1-4).

In this article, we are presenting a case of a leukemic pediatric patient in whom a central venous catheter was placed using prilocaine as an anesthetic prior to the procedure and who developed acute cyanosis and toxic methemoglobinemia within 30 min of medication administration.

\section{Case Report}

A 10-month-old male patient with a history of juvenile myelomonocytic leukemia (JMML) presented to our clinic with massive hepatosplenomegaly and decreased white blood cell count. Treatment plan included routine chemotherapy following protocol. Because of difficult intravenous access related to long-term chemotherapy, placement of central venous catheter was scheduled. Under the supervision of an anesthesiologist, Ketamin (Ketalar-Phizer, Kırklareli, Turkey) (1-3 mg/kg) was administered for sedation and prilocaine (Citanest; Zenica Medical, Paris, France) (1-2 mg/kg) was administered for local anesthesia. Ultrasound (Acuson S2000; Siemens, Erlangen, Germany) and fluoroscopy-guided subcutaneous chest port was placed via the right internal jugular vein (Polysite Micro, Pereous Laboratories, Ivry-Le-Temple, France). Echocardiogram (Vivid S5;GE. Healthcare, Wauwatosa, U.S.A.) taken before chemotherapy and port placement was normal.

Immediately following the placement of the port, the patient had developed severe cyanosis. Pneumothorax was considered as the initial differential diagnosis. Auscultation revealed clear breath sounds bilaterally, and posterior-anterior plain lung X-rays revealed no pathologic findings (Figure-1). The vital signs observed immediately following the procedure were as follows: heart rate, 178 beats/ min; respiration rate, 66 breaths $/$ min; body temperature, $36.7^{\circ} \mathrm{C}$; and oxygen saturation $\left(\mathrm{SaO}_{2}\right), 60 \%-70 \%$. Results of the arterial blood gas were as follows: $\mathrm{pH}, 7.39 ; \mathrm{pCO}_{2}, 34 \mathrm{mmHg} ; \mathrm{PO}_{2}, 110 \mathrm{mmHg}$; and $\mathrm{HCO}_{3}, 23 \mathrm{mEq} / \mathrm{L}$. The biochemistry panel showed the following results: blood sugar, 78 mg/dL; Sodium (Na), $135 \mathrm{mEq} / \mathrm{L}$; Potassium (K), $3.8 \mathrm{mEq} / \mathrm{L}$; Calcium (Ca), $8.8 \mathrm{mg} / \mathrm{dL}$; Blood Urea Nitrogen (BUN), $22 \mathrm{mg} / \mathrm{dL}$; and Creatine (Cr), $0.9 \mathrm{mg} / \mathrm{dL}$. The blood sample collected was dark brownish-red.

Methemoglobinemia was considered as a differential diagnosis when cyanosis and oxygen saturation level did not improve after the delivery of $100 \%$ oxygen using balloon mask, despite normal arterial blood gas levels.

After testing the methemoglobin level, patient was diagnosed with methemoglobinemia. Intravenous ascorbic acid (Redox; Bayer, Istanbul, Turkey) (C-vi10 mg/kg) was administered instead of methylene blue because of the unavailability of methylene blue at the institution and also considering the high rate of glucose-6-phosphate dehydrogenase (G6PD) deficiency in Turkey. Cyanosis improved following the administration of ascorbic acid and $\mathrm{SaO}_{2}$ level increased. The level of G6PD was normal when measured after the event.

\section{Discussion}

Methemoglobin that forms in healthy individuals after exposure to oxidants, including certain drugs, toxins, and chemicals is usually

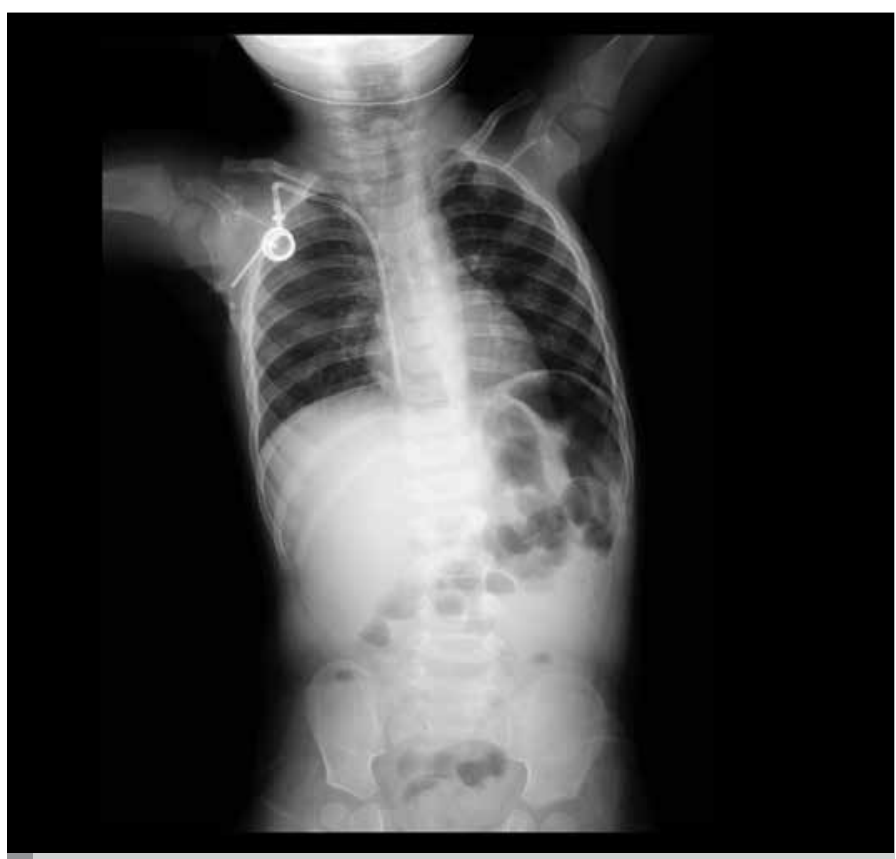

Figure 1. Posterior-anterior lung X-ray that revealed no pathologic findings.

less than $1.5 \%-2 \%$. It is controlled by the methemoglobin-reducing system, namely the cytochrome b5 reductase. The balance between oxidation and reduction can be impaired because of increased exposure to oxidants, abnormal hemoglobin, or excess methemoglobin level. Because the methemoglobin reductase activity during the first 3 months of life is low and fetal hemoglobin is more readily oxidized, the risk of developing methemoglobinemia from exposure to toxic substances is higher. Literature reviews indicate that children, particularly newborns, have the highest occurrence rate $(1,2)$.

Methemoglobinemia, which is characterized by increased blood methemoglobin level causing decreased oxygen delivery to tissues, is a hematologic emergency. Young children with cyanosis, particularly after invasive procedures, should be tested for methemoglobinemia (5). The most frequent cause is the application of oxidizing agents to the skin or mucous membranes. Some of the oxidizing agents directly cause methemoglobinemia, whereas other oxidizing agents cause methemoglobinemia through free oxygen radicals found in the environment (1-6).

Sufficient oxygen saturation in the arterial blood, despite marked cyanosis, and the absence of other etiologies are important clues for diagnosis. Definitive diagnosis is possible by applying co-oximetry that measures the methemoglobin absorption in blood. In addition, fragmented red blood cells, spherocytes, and Heinz bodies appear to be hemolyzed on peripheral blood smear because of oxidative stress $(1,2)$.

When the methemoglobin level exceeds normal limits, approximately at 10\%-20\%, cyanosis becomes apparent. With methemoglobin level between 20\% and 50\%, vertigo, headache, weakness, nausea, vomiting, shortness of breath, and tachycardia develop. Lethargy, stupor, and syncope are observed with values exceeding $50 \%-70 \%$. Half-life of methemoglobin is 55 min on an average. Met- 
hemoglobinemia starts to develop within 20-60 min following drug administration (1-3).

Congenital methemoglobinemia is quite rare. It can be observed with variant $\mathrm{HbM}$, nicotine adenine dinucleotide (NADH) diphorase enzyme (NADH diphorase) deficiency, and glucose-6-phosphatase deficiency; it can be rarely observed with cytochrome b5 reductase enzyme deficiency (2-5). Variant HbM has autosomal dominant inheritance. If the defect is in the alpha chain, cyanosis starts at birth and continues for lifetime. If the defect is in the beta chain, cyanosis is observed after 3 months post-partum; cyanosis disappears as hemoglobin matures. Central cyanosis is frequently observed in variant $\mathrm{HbM}$ cases. Diagnosis is made using hemoglobin electrophoresis $(1,2,6,7)$.

Acquired methemoglobinemia is mostly reported in the pediatric group. Although rare, it can also be observed in adults. Numerous chemicals and drugs have been reported to cause methemoglobinemia, including nitrites, nitrates, chlorates, quinines, aminobenzenes, nitrobenzenes, nitrotoluenes, phenasetin, phenitoin, dapson, chloroquine, sulfonamides, and local anesthetics. However, the most frequently reported are local anesthetics, sulfonamides, and vegetables containing nitrates $(1,2,6-9)$.

Prilocaine is a local anesthetic frequently used in the pediatric age group, possibly causing methemoglobinemia via its metabolite, otoluidine. Both parenteral and local forms of prilocaine-lidocaine are commonly used. Although therapeutical dosages $(1-2 \mathrm{mg} / \mathrm{kg})$ of prilocaine may cause methemoglobinemia without cyanosis (1-2 $\mathrm{mg} / \mathrm{kg}$ ), the risk of methemoglobinemia increases with increased dosage of prilocaine $(>3 \mathrm{mg} / \mathrm{kg}$ ). A few cases in which severe methemoglobinemia developed after the use of therapeutical dosages of prilocaine have also been documented in the literature $(1,2,5,9)$.

When methemoglobinemia related to local anesthetic application is considered, local anesthetic administration must be immediately stopped and, if possible, removed from the body. If the methemoglobin level is under 20\%, spontaneous improvement is observed with the discontinuation of drug. However, if the blood methemoglobin level is over $20 \%$ and the patient is symptomatic, or if the methemoglobin level is over $30 \%$ and the patient is asymptomatic, the patient must always be treated. The first choice of treatment in methemoglobinemia related to local anesthetic usage is methylene blue infusion. Methylene blue must be administered together with glucose to be effective, and the glucose cycle that is the NADH source for red blood cells must function normally $(1-4,8,9)$.

Leucomethylene, a metabolite of methylene blue, is an oxidizing agent. It can cause hemolysis in high dosages. Particularly in patients with G6PD enzyme deficiency, the severity of methemoglobinemia can be worse because of oxidation. Intravenous ascorbic acid can be used in place of methylene blue when it is not available. Ascorbic acid reduces methemoglobin via a non-enzymatic pathway in vitro. It is orally administered, thereby facilitating long-term use in hereditary methemoglobinemia (3-5).

Since 2004, over 300 subcutaneous jugular ports have been placed by the interventional radiology department at our hospital. Nevertheless, only one case of methemoglobinemia has been document- ed in our clinic. While conducting literature review, we did not find any similar cases of methemoglobinemia related to subcutaneous central venous catheter placement.

In the case, our initial differential diagnosis for severe cyanosis that developed following central venous catheter placement was pneumothorax related to procedure. When methemoglobin level was revealed to be $41.2 \%$, treatment was initiated immediately. High occurrence rate of G6PD enzyme deficiency in Turkey was also taken into consideration. Because of this result as well as because of the lack of access to methylene blue, intravenous ascorbic acid was administered as an alternative.

\section{Conclusion}

Many drugs and chemical agents used in clinics for treatment can cause methemoglobinemia. In particular, prilocaine used as local anesthesia in newborns and pediatric patients is a common causative agent. This is an emergency that must be considered as a part of differential diagnosis for pediatric patients when severe cyanosis is present without an effect on oxygen saturation and no other pathologies are suspected.

Access to the methylene blue, which is the basis of the treatment, is difficult in Turkey. In addition, the deficiency of G6PD enzyme that requires the use of ascorbic acid is specific to our region. Methylene blue, which is critically important, must be available in certain centers; in addition, the treatment of the patient must be planned by taking regional risks into consideration.

Informed Consent: Written informed consent was not obtained from patient who participated in this case.

Peer-review: Externally peer-reviewed.

Author Contributions: Concept - B.S.K., E.P.; Design - B.S.K.; Supervision - B.S.K., Y.K., E.A.; Materials - B.S.K., E.A.; Data Collection and/or Processing - B.S.K., E.P., E.A.; Analysis and/or Interpretation - B.S.K., E.P., Y.K., E.A.; Literature Review - B.S.K., E.P.; Writer - B.S.K., E.P.; Critical Review - Y.K., E.A.

\section{Conflict of Interest: The authors declared no conflict of interest.}

Financial Disclosure: The authors declared that this study has received no financial support.

\section{References}

1. Honig GR. Hemoglobin disorder, in Nelson Textbook of Pediatrics, Behrman RE, Kleigman RM, and Jenson HB. USA, Philadelphia: Saunders Elsevier: 2000: p. 1478-88.

2. Skold A, Cosco DL, Klein R. Methemoglobinemia: pathogenesis, diagnosis, and management. South Med J 2011; 104: 757-61. [CrossRef]

3. Turkmen E, Kocabay G, Yavuz AS. Acaseofmethe-moglobinemia induced by the administration of prilocaineprior to an epilation procedure. Journal of 1st Faculty of Medicine 2005; 68: 19-21.

4. Coleman MD, Coleman NA. Drug-induced methemoglobinemia. Drug Saf 1996; 14: 394-405. [CrossRef]

5. Benini D, Vino L, Fanos V. Acquired methemoglobinemia: a case report. Pediatr Med Chir 1998; 20: 411-3. 
6. Ozdogan H, Osma S, Aydin GB, Dinc A, Ozgun G. Methemoglobinemia presenting in a circumcised baby following application of prilocaine: a case report. J Med Case Rep 2010; 10: 49. [CrossRef]

7. Ergül Y, Nişli K, Kalkandelen S, Dindar A. Acute cyanosis after transcatheter balloon valvuloplasty: toxic methemoglobinemia due to local prilocaine use. Turk Kardiyol Dern Ars. 2011; 39: 64-7.
8. Tantisattamo E, Suwantarat N, Vierra JR, Evans SJ. Atypical presentations of methemoglobinemia from benzocaine spray. Hawaii Med J. 2011; 70: 125-6.

9. Kaczorowska-Hac B, Stefanowicz J, Stachowicz-Stencel T, Kozlowska M, Adamkiewicz-Drozynska E, Balcerska A. Methemoglobinemia in postchemotherapy stomatitis topical treatment: 2 pediatric cases. J Pediatr Hematol Oncol. 2012; 34: 137-9. [CrossRef] 